\title{
BERNARD, E. E. \\ A REVIEW OF THE APPLICATION OF ELECTROMAGNETIC FIELDS ON MICROBES FOR SURFACE SANITARY WIPES.
}

\author{
benemesengineering@gmail.com \\ Technology Park, Research Management and Development, University of Port Harcourt, Choba. \\ This article is covered and protected by copyright law and all rights reserved exclusively by the \\ Centre for Petroleum, Pollution Control and Corrosion Studies (CEFPACS) Consulting Limited. \\ Please note that the opinion expressed in this article remain that of the author(s). \\ Electronic copies available to authorised users.
}

The link to this publication is https://ajoeer.org.ng/otn/ajoeer/qtr-1/2021/09.pdf 


\title{
A Review of The Application of Electromagnetic Fields on Microbes for Surface Sanitary Wipes.
}

BERNARD, E. E.

\section{Technology Park, Research Management and Development, University of Port Harcourt, Choba. benemesengineering@gmail.com}

\begin{abstract}
.
The approach in the use of electromagnetic fields (EMFs) has shown antimicrobial effects in different frequencies and intensities. So far, different modalities of EMFs showed antimicrobial and antibacterial effects in different pathogens. However, a novel approach in the use of the EMFs on microbes was carried out using elaborate experimental set up. Apart from the inclusion of ionic $\mathrm{pH}$ medium, a short cylindrical pipe was inserted to a short iron core of the same concentric center to form a space in between. Void materials of glass pebbles activated charcoal and saline water (Gel) was filled to the space respectively in accordance with the three experimental set-ups. A coil of wire was inserted around the iron core with the terminals connected to a $12 \mathrm{v}$ rechargeable finger battery. These three novel EMFs approaches were conducted under normal prevailing temperature and each of the experimental set up was tested on a table surface infected with pathogens. The novel results showed that the destruction of microbes was $99.9 \%$ in faster and better than the prior methods. These results of these experiments will pave way for the optimal industrial application of EMFs to make surface sanitary wipe efficient and effective in Nigeria.
\end{abstract}

Keywords: Electromagnetic Field. Surface Wipes, Microbes, Frequency, Radiation.

\section{0: INTRODUCTION}

The first study on the impact of electromagnetism on organism dates back to the nineteenth century, Sakakiuar et al (1993) and schoenbach et al (1997). This then intensified in the following decades after global electrification and the diffusion of telecommunication. The massive introduction into daily life of technologies that emit electric, magnetic and electromagnetic in an enormous range of frequencies and intensities led institutions and scientific community to question itself about the effect on public health and the environment. Pertinent to say, scientific literature is very vast and includes studies that vary greatly on the type of field and intensity, exposure duration, long/short term effect and considered biological target (cells, tissues, organ and organisms), Consterton et al, (1994).

Electromagnetic fields (EMFs) have a major impact on biological systems. Panagopoulus et al (200), Grassi et al (2004) states that studies on the effect of magnetic fields on prokaryotes have recently increased significantly, including studies on the effects of static magnetic fields, short frequency electromagnetic fields. Fojt et al (2004) for example detected a decrease in colony forming units of E.coli, S aureus and L.adecarboxylat at 50Hz.10MT (particularly short frequency electromagnetic fields), while Strasak et al (1998) reported that exposure of E.coli to extremely low frequency electromagnetic fields for $0-24 \mathrm{~h}$ decreased the viability and growth rate of this bacteria when subjected to $50 \mathrm{~Hz}$, static magnetic fields have also been shown to 
inhibit bacterial growth Chang et al, 2005, El-Sayed et al, (2006), Paitti et al (2002). Segatore et al (2012) determined the effect of particularly short frequency electromagnetic fields (El-FEMF) on antibiotic sensitivity and growth rate in P. aeruginosa and E. coli. electromagnetic fields (EMF) exposure significantly affected the growth rate of P.aeraginosa and E'coli when incubated with subinhibitory concentrations of KanamyCin $(\mathrm{mg} / \mathrm{ml})$ and amikacin $(05 \mathrm{mg} / \mathrm{ml})$ individually.

The potential of a synergistic and/or antagonistic impact on bacteria of antibiotics and exposure to electromagnetic fields deserves special attention because of antibiotics resistance Bush et al (2011).

This research is expected to provide the best practice in curbing the upsurge of surface resident microbes, especially in offices, homes, social gatherings, and worship centers. This is much necessary because of the novel Covid-19 pandemic and future upsurge of new strains of microbes in the environment. Domingo E. Holland J. (1994), Brasser. et al (2002). This project is providing a method whereby material surfaces could be disinfected using electromagnetic sanitary wipes. This will also replace the old format of using a piece of cloth as rag to clean the surfaces of office tables. Kundrapu S. et al (2012). Rags are found to infect surfaces with microbes rather than disinfecting them.

\section{0: LITERATURE REVIEW}

This discusses the works of authors on the effects of electromagnetic fields on microbes. However, to enable full understanding of this review, it is very necessary to explain their EMFs and the ranges in frequencies and intensities, Fort.L. et al (2004)

To explain the EMFs effects, we can classify EMFs into seven categories (i) EIF (0$300 \mathrm{M}) \mathrm{HZ}$ ), used for biological process, (ii) very frequency (30KHZ- 30MHZ), used for armature radio and remote control; (iii) ultra-high (30-300GHZ), used in radio and television; (iv) super high (300 MHZ - 30GHZ) used in satellite communication. (v) extreme high frequency (30 300 GHZ), used in radar; (vi)Infrared (300GHZ - 300THZ); and (vii) visible light (429750THZ) used in high spectrums. P. Free et al (2010).

In the following, the antimicrobial and anti-bacterial effects of EMFs in the two main categories are reviewed: High frequency low intensity EMFs.

\section{1: High Frequency Low Intensity EMFs}

Complex network of sensing and responding to physical and chemical factors is used by living cells, especially by bacteria, to communicate with each and to survive under different environmental conditions. It was suggested that electromagnetic irradiation (EMI) of extremely high frequency (30-300GHZ) with low intensity at specific resonant frequencies can affect bacteria in the manner of energy transformation into informative signals (70-73GHZ), P. Free et al (2010).

Accumulating data explain the potential of low intensity coherence EMI of resonant frequencies to cause depressing effects on E. coli which considered the best characterized bacteria and a model organism. The effects mainly depend on intensity irradiation and exposure, the combination of growth and irradiation of the genetic features of strains, the coordinates of bacteria metabolism and other factors. In addition, these effects can regulate the mutual reaction 
of organisms against impact of physical and chemical factor. A mutation in the growth cycle of bacteria is possible due to metabolic processes or mechanical resonance. P.V. Zinin et al (2005).

It is known that E. coli growth can be decreased at specific frequencies of low intensity EMI from the range of 45-53 GHZ and of 70-75GHZ, Costerton et al (1994). One of the possible interaction mechanisms with such EMI is Gene targeting. However, the energy resulting from these frequencies is not sufficient to break a chemical bond in DNA. It is possible that EMI at levels can create oxygen radicals or disorder process of DNA. It is possible that EMI at these levels can create oxygen radicals or disorder process of DNA repair, Phillip J.L. et al (2009). The elastic forces in the walls of cell membranes help to weaken the oscillating forces by participating in coherent self -sustained oscillation that leads to possible macro- molecular conformational transitions that are fed with metabolic energy.

\section{2: $\quad$ Low Frequency Magnetic Field}

One of the current and useful method to investigate anti- bacteria effects of EMFs is to use low frequencies especially frequencies ranging $50 \mathrm{HZ}$ to $60 \mathrm{HZ}$. Various studies have been published on the effects of these fields. However, contrary to the publications claiming the bioeffects of EMFs, plenty of studies have shown no significant effects on the living organisms. Lopucki et al (2005) reported that no change in oxidative DNA damage after $50 \mathrm{HZ}$ MF exposure was found.

\section{3: Extremely Low Frequency}

Various works have been done on the effects of ELF, EMFs on biological systems. The results of ELF - EMFs research are contradictory, and little is known about the possible mechanisms of interaction between ELF- EMF and living mechanism. Standard methods such growth and protein synthesis, were used to survey the effect of ELF - EMFs on bacteria and specially designed methods were employed to test the influence of ELF- EMFs on bacterial bioluminescence. ELF, EMF has few effects on bacteria, Dunlap, P.V. (2014) and Engelbrecht, et al (1983).

\section{4: Dependence of Colony Forming Units (CFU) on Exposure Time}

Strasak et al (1998) and Foj et al (2004) investigate the effects of low frequency on bacteria and reported that the number of CFU decreases with the time of exposure and they found $20 \%$ decrease in CFU number for Gram - positive 30\% decrease in CFU number for Gram positive. Falone et al (2007) used extremely low frequency (EFL) EMF, 50HZ, in neuroblastoma cells and it was found that low frequency magnetic exposure increased viability of SH-SY5Y in a time dependent manner when compared to controls. Novak et al (2005) showed that MFs reduce optical densities of the S. Cerevisae. Reviewing the related studies, it can be exerted immediately after the exposure to the yeast culture.

\section{5: Effects of Microbes in Electric Fields with Ionic Medium pH}

The microbial inactivation by PEF technology is extremely influenced by the strength of ionic and medium $\mathrm{pH}$. When the medium has a low ionic strength, the inactivation ratio is usually increased. Veg-Mercado et al (1996) consider that the ionic strength and $\mathrm{pH}$ disturb the homeostasis of the micro - organisms leading to an increase of the inactivation ratio. Increasing the ionic force leads to an increment in the electron mobility through solution and reduction in the micro - organisms' inactivation by PEF treatment. Tsong (1991), reported that the reduced 
inactivation rate in high ionic force solutions can be described by the cell membranes stability when they are exposed as a medium which includes several ions. The ions which dissolved in the treated medium such as $\mathrm{Ca}^{2+}, \mathrm{Na}^{+}, \mathrm{K}^{+}, \mathrm{Mg}^{2 \mathrm{t}}$ have been found to reduce the effects on microbial inactivation with EF. Bruhn et al (2016), found that the presence of ions in a medium looks to be necessary to increase the trans-membrane potential. Some researchers have demonstrated that in acidic medium, micro- organisms are more sensitive to the PEF. Other investigators have shown that resistance of microbes are lower at natural $\mathrm{pH}$ and with no influence on microbial EF inactivation. These differences have not been definite yet, but researchers could be correlated with the increasing number of pulses and EF power applied at the medium which has lower $\mathrm{pH}$, the micro-organisms type and the change in the cell ability to maintain a trans-membrane $\mathrm{pH}$ gradient because of membrane electroporation. The medium $\mathrm{pH}$ plays a significant role in microbial inactivation when EF is combined with organic acid treatment having antimicrobial effect.

\section{6: Experiments and Results}

Belis et al (2004) studied and compared the effects of cell growth to 50HZF with intensity of $0.5 \mathrm{~T}$ and the SMFs in the range of $0.1-100 \mathrm{nT}$ on sacharonycescerevisial strains. The assessment measure was duplication time. They found that there were exposed and not exposed. But the experiment was not able to detect smaller changes in the growth of the yeast. It seems that colonyforming units $(\mathrm{CFU})$ counting is a better techniques to assess the growth rate of S.cerevisial.

Wenji et al (2009) used SMFs on E. coli the experiment suggested that the SMF inhibited the growth and propagation of E. coli cells greatly or even killed large number of the cell during the initial stage of SMF treatment. Moreover, Wenji et al found that the E. coli cells were most sensitive to the SMF at a higher temperature because the relative number of CFU decrease with membrane theory. This theory expresses that the diamagnetic properties of membrane phospholipids determine the SMFs effects on living organisms. The reorientation of these molecules during SMFs exposure will result in the deformation of excitation of the hydrocarbon chain that occurs, and this makes the reorientation of the molecules much easier. Therefore, the SMFs effects on organisms are enhanced.

Weimin et al (2005) found that $12 \mathrm{hrs}$ exposure of the 14 ITMF has no detectable effect on the cell growth of S.oneidensis, and this result was different from the result Horiuchi et al (2001) on E.coli cultured. Horiuchi et al (2001) found that the number of viable cells of E. coli $\mathrm{B}$ in the stationary phase after $48 \mathrm{hrs}$ under the MF of 5.2-6.1T was 100,000 times higher than that under a geomagnetic field.

Kohno et al (2000) explored the effect of SMF on some culture of such bacteria streptococcus nytans, staphylococcus aureus, and Eschericlia coli. They reported that when culture under anaerobic conditions, the tertrite magnet caused strength dependent decreases in the growth rate and maximum number of bacteria for S.natans, S.aureus, but their growth was not inhibited under aerobic conditions. The result indicated that the S.mutans and S.aureus growth are dependent on oxygen.

Stansel et al (2001) reported that SMF can lead to significant increase in the antibiotic resistance of E. coli. 


\section{7: Transmission Electron Microscopy (TEM) And Scanning Electron Microscopy (SEM) Assessment}

In order to identify why the SMFs affect the viability of E. coli cells, transmission electron microscopy (TEM) and scanning electron microscopy (SEM) are used. These two instruments showed that the cells surface was damaged while exposed to SMFs. The untreated cells surface was smooth while the treated cells surface was brethren at the cell two ends. This might be caused by strong oxidation effect of oxygen free radicals which were produced by SMFs treatment. There were three main theories to explore the explicate, the effects of SMFs on living organisms (i) ion interface mechanisms (paint) SMF affects the binding state of nonprotein complex. This theory indicates that the SMF does not cause any quantum transitions. It is just an interface effect of long-lied quantum states of the ion within the protein capsule. (ii) free radical theory: when the bacterial solution is exposed to the SMF, it creates oxygen free radicals. These free radicals include $\mathrm{h}_{2} \mathrm{O} ; \mathrm{O}_{3}, \mathrm{~h}_{2} \mathrm{O}_{2}$, etc. these compounds damage to the cells of living organisms are highly reactive so that it can cause great damage to the cells of living organisms. (iii) membrane theory: plasma membranes of cells are composed of diamagnetic anisotropy molecules. In the presence of SMF, the molecules. In the presence of SMF, the molecules will rotate and ultimately achieve an equilibrium orientation, representing the minimum free-energy state, Takehiko et al (2012).

The molecular rotation within the membrane matrix will influence embedded ion channels and therefore affect the ions mobility.

The phenomenon observed in the experiment described suggest that the effect of SMFs on the bacterial strain may be interpreted by a combination of these three theories.

Different strains of bacteria (Escherichia coli, protein vulgaris, plot bacteriumphosphoreuum, fisheri) were exposed to extremely 2-50HZ. The field strength was viewed from 1-10mT using sinusoidal wave forms Fojt et al (2009). The direction of exposure and temperature were varied. No growth, protein synthesis and lamibnescence of the bacteria were examined, no effect could be seen on the protein synthesis rate in 19 experiments using radioactively labeled leucine. The protein pattern was not affected in 15 experiments under standard temperature conditions using isoelectric focusing (IEF) and sodium dedecylsulphatepolycrlamide gel electrophoresis of $3.8 \%$ in 2 out of 23 experiments. The luminescence of the photobacteria was affected in out of 20 experimented at standard temperature. Combining electromagnetic fields with heat stress, effects on the protein pattern and luminescence were observed in more than $50 \%$ of the experiment. The results support the concept that bacteria are quite resistant to electromagnetic fields, probably because of compensation and self-regulation, Longton R.W. et al (1975).

From the experiments carried out by different researchers above, we can conclude that microbes are affected mostly when they are under the influence of electromagnetic fields domiciled in ionic $\mathrm{pH}$ medium. The strength of the field and the intensity with the exposure time are the basic functions, Xiaoxia Sheng et al (2008). 


\section{0: MATERIALS AND METHOD}

This research work tried to narrow down experiments using low frequency and low intensity electromagnetic fields on microbes with very minimum exposures. This is necessary to enable a proper focus on the practical application of electromagnetic field on microbes for surface sanitary wipe. However, the present experiments are connected to the existing research works elaborated so far in this article.

Furthermore, the materials and method of approach applied in this novel research may differ considerably with the prior arts, but the targeted aim is almost the same but with a $99.9 \%$ efficiency yielding to the purpose it is demanded for.

This research work is conducted in such a manner that is summarized in a table on minimal exposure to electrostatic fields/field generated by direct current (DC). The discussion was made to treat electrostatic fields applications (typically generated while maintaining a constant voltage between pairs of electrodes) together with the source are applied to dielectric means (material surface, etc.) they produce similar effects, even in most of the literature that was analyzed, they are treated simultaneously with, without any distinction between the two situations except for the variant degree of efficacy on the microbes.

\section{1: EXPERIMENT1}

\subsection{1: Enhanced destruction of pathogens by novel inclusion of glass beads in ionic medium pH EMFs}

The materials used for this experiment are made of a small diametric metal pipe of $1 / 2$ " and 2 " long; a concentric inner and outer electrodes; Glass beads; Dielectric liner; a 12v alkaline rechargeable finger battery; a Coil of wire in a symmetric dimension; a short piece of Iron core of a correlating dimension and a small air suction electric motor.
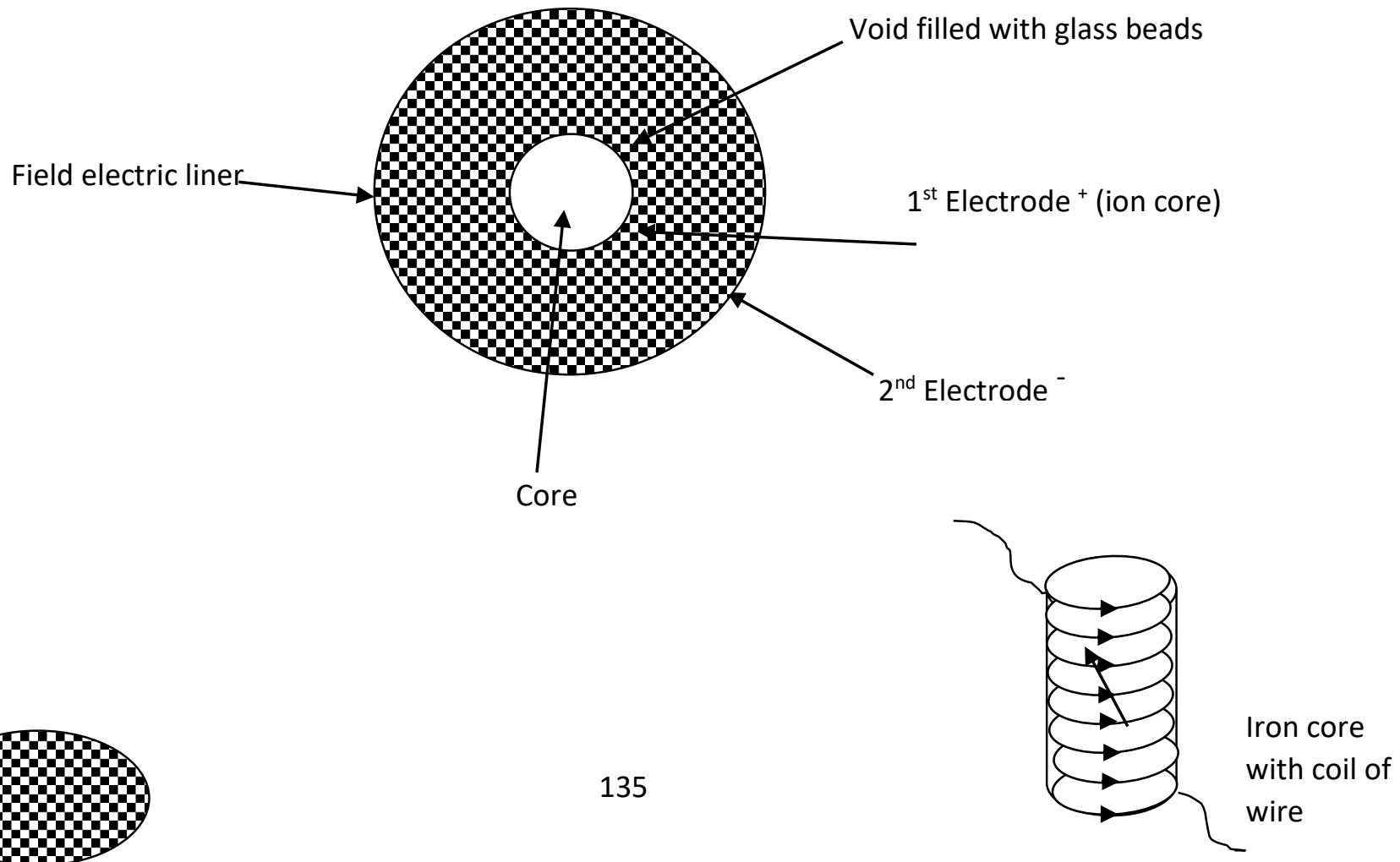


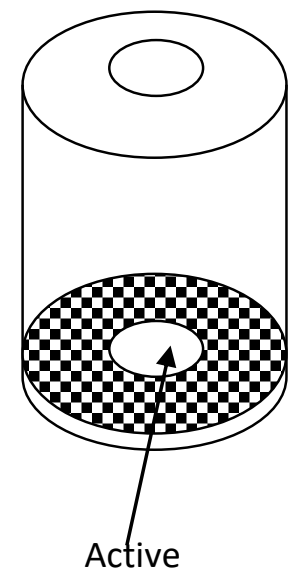

hole

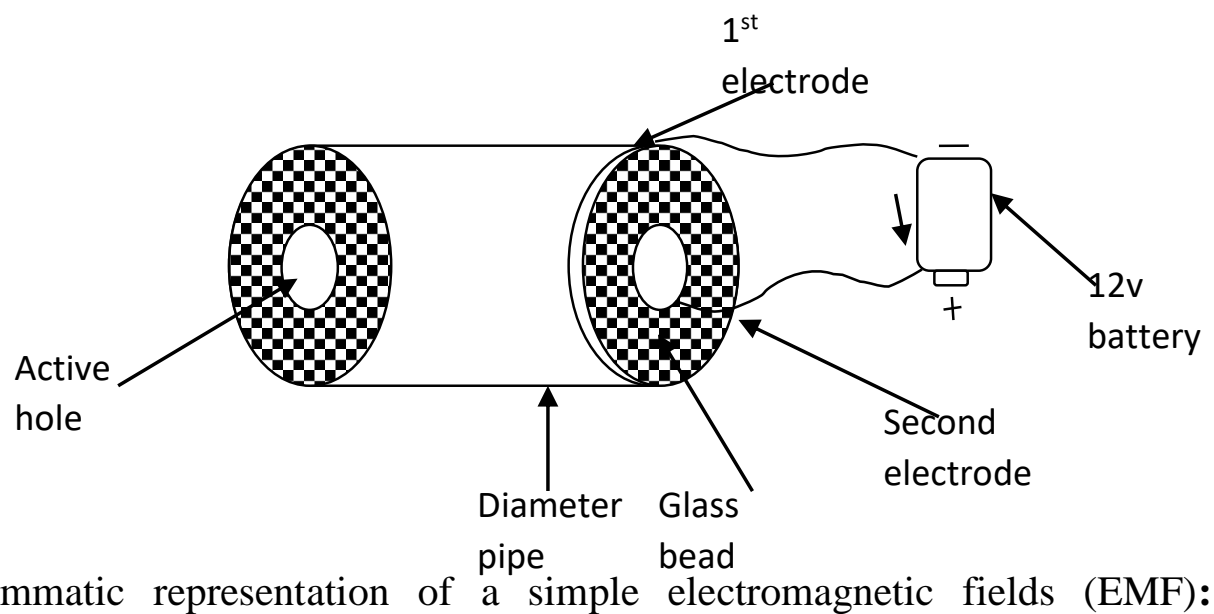

Adapted from Bernard Eme's Invention.

The simple pipe is filled with glass beads while the iron core is fixed at the center to create an open hollow. Electrical terminals are fixed at the pipe and another point fixed to the iron core wrapped with copper wire. These two points serves as the positive and negative electrodes. The terminals are connected to the to the Dc battery. This is summarized in the table below:

Table 1: Enhanced Destruction of microbes by novel inclusion of glass beads.

\begin{tabular}{|l|l|l|l|l|l|}
\hline Culture & Current & Fields & $\begin{array}{l}\text { Exposure } \\
\text { duration }\end{array}$ & Source & $\begin{array}{l}\text { Biological effects and } \\
\text { results }\end{array}$ \\
\hline $\begin{array}{l}\text { Escherichia. Coli } \\
\text { staphylococcus } \\
\text { aereus bacillus fungi } \\
\text { (yeast) virus }\end{array}$ & $10-40 \mathrm{MA}$ & & $\begin{array}{l}10-20 \\
\text { seconds }\end{array}$ & $\begin{array}{l}\text { Dc supply with } \\
\text { two electrodes } \\
\text { connected to } \\
\text { negative and } \\
\text { positive } \\
\text { terminals of } \\
\text { supply. }\end{array}$ & $\begin{array}{l}\text { The up resulted in 97 } \\
\text { percent E.coli inactivation } \\
99.9 \% \text { virus was trapped and } \\
\text { destroyed. All the microbes } \\
\text { under test examination were } \\
\text { all destroyed and rendered } \\
\text { inactive in split seconds of } \\
\text { exposure of the electric field } \\
\text { force. }\end{array}$ \\
\hline
\end{tabular}

This device looks like a simple pipe, but inside it is filled with glass beads responsible for capturing these tiny little discharges. As electricity flows through the system, electrons are sent flying and atoms are pulled from their molecules, producing a silent flow. The result is host of free radicals which are highly reactive particles desperate to reach a stable equilibrium by forming new compounds. The oxygen radical is particularly excited, and when it reacts with a normal molecule of oxygen at room temperature, it rapidly forms ozone, a known antibacterial agent. (TEM) and (SEM) assessment

Also, in these void spaces you are initiating sparks by passing through the packed bed, pathogens in the immediate environment are oxidized by unstable atoms called radicals. These radicals initiate the oxidation of the microbes, killing them eventually in split seconds. (Free Radial Theory). 


\section{2: $\quad$ EXPERIMENT 2}

\subsection{1: Enhanced destruction of pathogens by novel inclusion of Ethanol and emulsified} sodium chloride in ionic medium pH EMFs.

The materials used for this experiment includes; a concentric coil of wire; a unit $12 \mathrm{v}$ alkaline rechargeable finger battery; Iron core of correlating dimension; a Zinc \& copper electrodes of a common center; ethanol $\left(\mathrm{C}_{2} \mathrm{~h}_{6} \mathrm{O}\right)$; sodium chloride $[\mathrm{Na}+\mathrm{cl}-]$ and water $\left[\mathrm{H}_{2} \mathrm{O}\right]$.

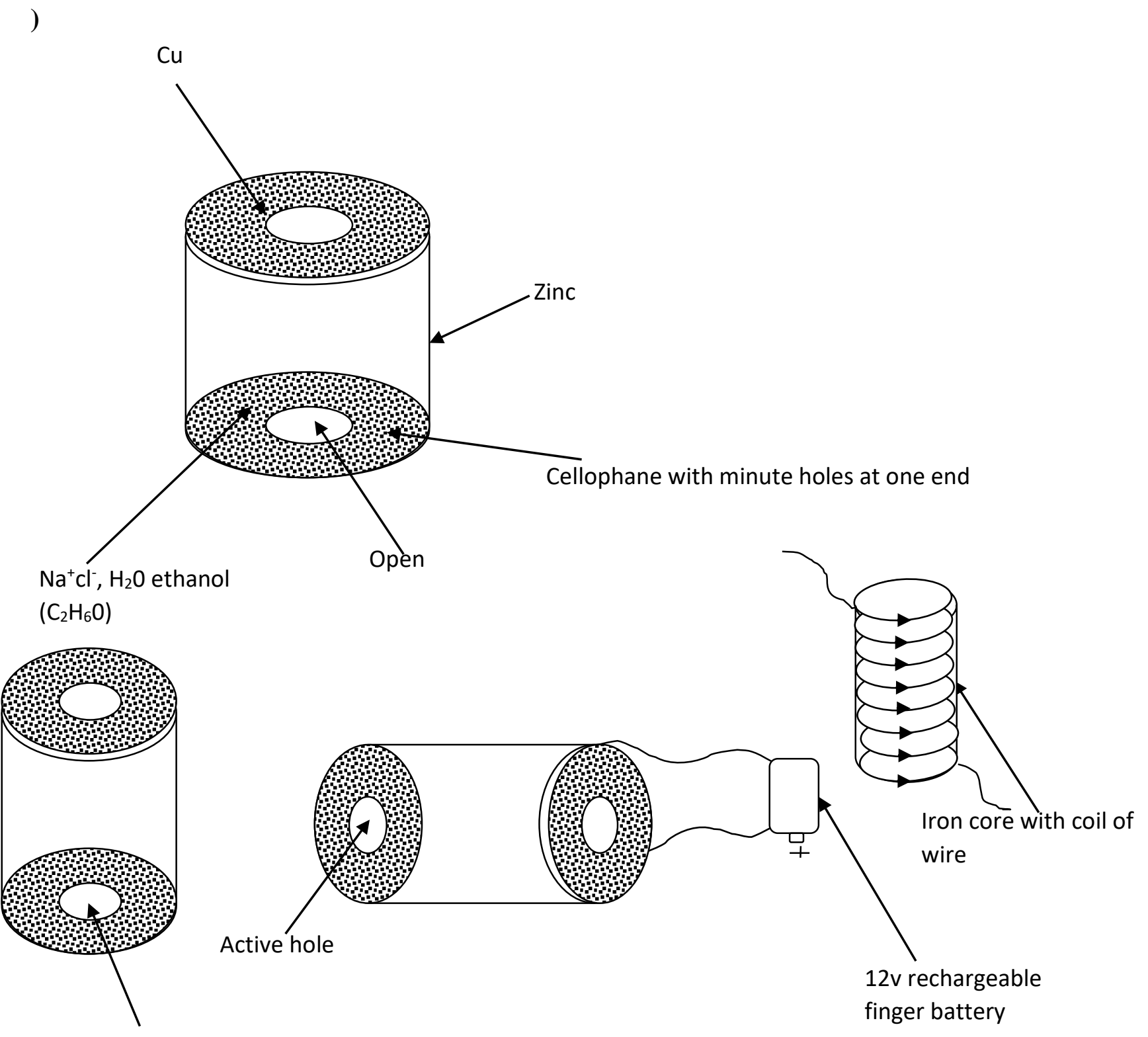

Active hole 
Diagrammatic representation of a simple electromagnetic field (EMF : Adapted from Bernard Eme's Invention

Method: Two concentric electrode made up of electrolytic cell, while the zinc electrode enclosed the electrolytes made upon sodium chloride gel, the copper electrode in other hand is wrapped in iron core and coil of wire for electromotive force drive.

When a direct current of 10-40MA is passed through the terminals, the electrolyte assumes a die phase charges migrating to their demanding electromagnetic field, whose intensity increases with slight increase in current. The electric field build-up is concentrated at the central open core. When the open core is made in contact with the microbes, in a split second, the microbes are rendered inactive and $99.8 \%$ will all die. This is summarized in the table below:

Table 2: Enhanced destruction of microbes by novel inclusion of ethanol sodium chloride

\begin{tabular}{|c|c|c|c|c|c|}
\hline Culture & Current & Fields & $\begin{array}{l}\text { Exposure } \\
\text { duration }\end{array}$ & $\begin{array}{l}\text { Source and field } \\
\text { source }\end{array}$ & $\begin{array}{l}\text { Biological effects and } \\
\text { results }\end{array}$ \\
\hline $\begin{array}{l}\text { Escherichia. Coli, } \\
\text { listeria, innocua, } \\
\text { staphylococcus } \\
\text { aereus listeria } \\
\text { mesenteroid virus }\end{array}$ & 10-40MA & & $\begin{array}{l}10-20 \text { pulses } \\
\text { of } 2-4 \mathrm{~ms} \text { at a } \\
\text { frequency of } \\
250 \text { pulses }\end{array}$ & $\begin{array}{l}\text { Dc supply with two } \\
\text { electrolytic } \\
\text { electrodes } \\
\text { connected to '+' and } \\
\text { '-'terminals of set } \\
\text { up electrolyte made } \\
\text { up of } \mathrm{Na}+\mathrm{cl}-\text {, } \\
\mathrm{C} 2 \mathrm{H} 6 \text { ) and } \mathrm{H} 20 \text { in a } \\
\text { gel format made up } \\
\text { of copper and zinc }\end{array}$ & $\begin{array}{l}\text { Microorganism inactivation } \\
\text { increasing with the electric } \\
\text { fields' intensity, duration } \\
\text { and number of applied } \\
\text { pulses. Even though with } \\
\text { positive effects on almost the } \\
\text { microbes examined, a } \\
\text { different susceptibility was } \\
\text { noted with Listeria innocua } \\
\text { and Listertiameseteroid } \\
\text { being more resistant than E. } \\
\text { coli. }\end{array}$ \\
\hline
\end{tabular}

This experimental set up look like a simple electrolytic cell except on some other inclusive materials. One great advantage of this set up is the formation of temperature increase above laboratory temperature making the experiment to attain positive impact on the microbes.Wenjin et al (2001). The ethanol is also another good player in this set up; it enhances the speedy degradation of the outer cells of the microbes thereby killing them eventually. It will also interest you to know that the electromagnetic field is located at the core of the cylindrical set up. It is only the microbes that falls within the domain of the central core that gets affected by the electric field. from the experiment conducted, $99.2 \%$ of the microbes were destroyed apart from E. coli and the listeria innocular including listeria mesenteriod. The resistance theory; this theory expresses that the diamagnetic properties of membrane phospholipids determine the MFs effects on living organisms. 


\section{3: $\quad$ Experiment 3}

\subsection{1: Enhanced destruction of pathogens by novel inclusion of activated charcoal and emulsified sodium chloride in ionic medium}

The materials used for this experiment includes: a concentric coil of wire; a unit $12 \mathrm{v}$ alkaline rechargeable finger battery; Iron core of correlating dimension; a short piece cylindrical pipe; a zinc and copper electrodes (zinc and copper); Saline water and activated charcoal.

Diagrammatic representation of a simple electromagnetic field (EMF)
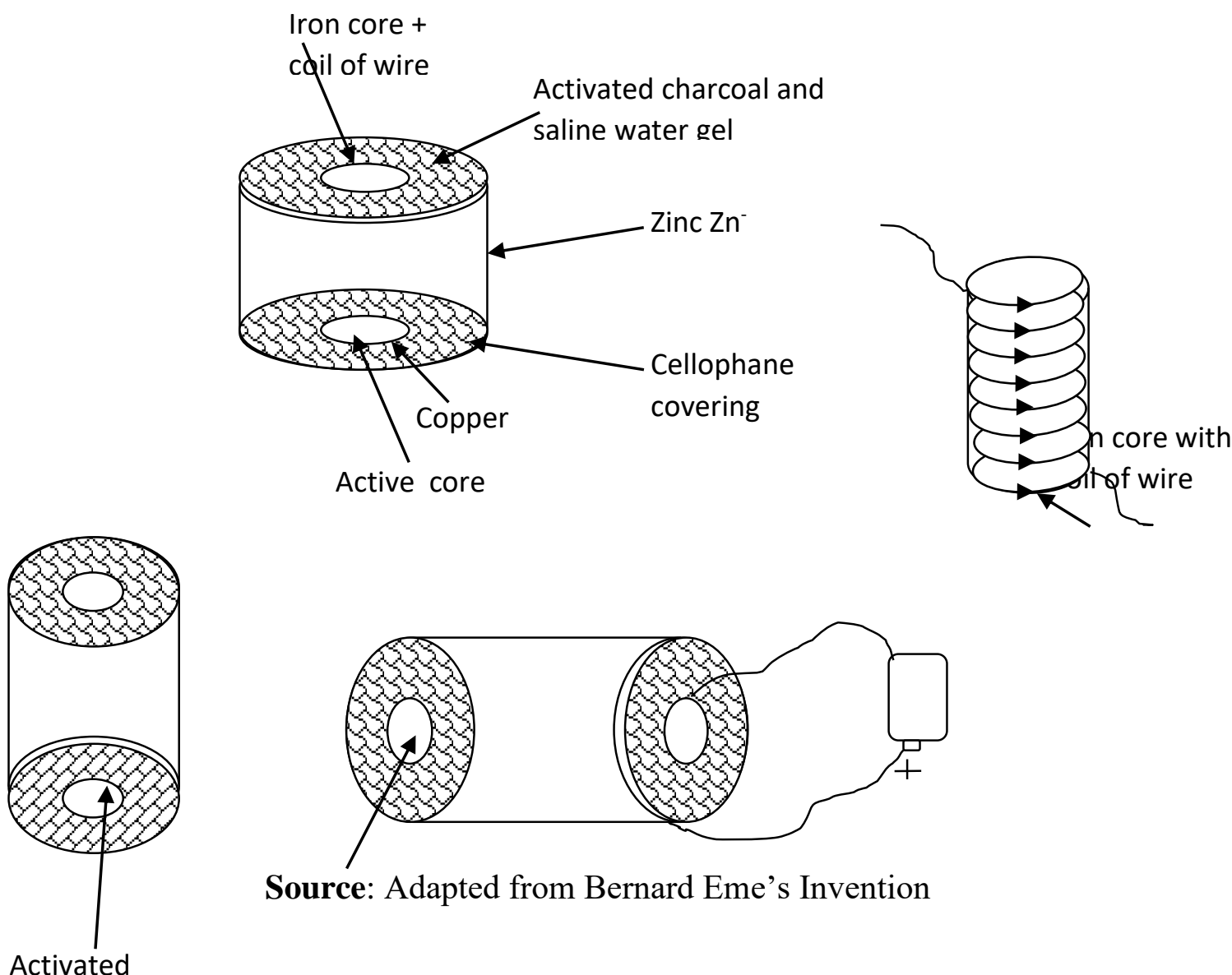

Source: Adapted from Bernard Eme's Invention

This experiment is related to the previous ones except for the substitution of the void components with saline water and activated charcoal. The void is enclosed by a cylindrical zinc material while the core constants of a cylindrical iron material wrapped round with a coil of wire with terminals at both ends. The basement of the setup is covered with cellophane to prevent fluid leakage. The electrical terminals are connected to the positive (+) and negative (-) pole of the battery, while the central core of the setup is focused to the central core of the setup is focused to the culture under experiment. The system brings about a strong electric field that yields good result. This is summarized below with a table. 
Table 3: Enhanced destruction of microbes by inclusion of activated charcoal

\begin{tabular}{|c|c|c|c|c|c|}
\hline Culture & Current & Fields & $\begin{array}{l}\text { Exposure } \\
\text { duration }\end{array}$ & $\begin{array}{l}\text { Set Up and field } \\
\text { Source }\end{array}$ & $\begin{array}{l}\text { Biological effects and } \\
\text { results }\end{array}$ \\
\hline $\begin{array}{l}\text { StaphillococcusAe } \\
\text { rreus Yeast } \\
\text { Mopuld, } \\
\text { Salmonella, E. coli } \\
\text { Rotavirus, } \\
\text { Rhinovirus, } \\
\text { hepatitis virus, } \\
\text { listeria } \\
\text { mensenteriod, } \\
\text { listeria innocua }\end{array}$ & $0.5-2 \mathrm{~A}$ & & 1-6 seconds & $\begin{array}{l}\text { Dry alkaline } \\
\text { rechargeable battery } \\
\text { with variable } \\
\text { voltage supply, coil } \\
\text { of wire iron core, } \\
\text { short cylindrical } \\
\text { pipe } \mathrm{Cu} \text { and Zn } \\
\text { electrodes saline } \\
\text { water and activated } \\
\text { charcoal. }\end{array}$ & $\begin{array}{l}\text { When the central core of the } \\
\text { set up was focused on the } \\
\text { microbes one after the other, } \\
\text { it was observed that almost } \\
\text { all the microbes were } \\
\text { affected up to the point of } \\
\text { death at a very short time } \\
\text { exposure of } 2 \text { seconds. The } \\
\text { only microbes that resisted } \\
\text { but suffered weakness and } \\
\text { immobility is listeria } \\
\text { mensenteriod and listeria } \\
\text { exposure time is increased to } \\
4 \mathrm{~s} \text { and field intensity doubled } \\
\text { all the microbes died. }\end{array}$ \\
\hline
\end{tabular}

\section{0: $\quad$ RESULTS AND DISCUSSION}

This experimental set up is just like the previous ones except for the substitution of void constituent with activated animal charcoal and saline water. This experiment offers the best positive result on microbes because of its strong effect on the microbes with a minimum exposure time. The reason for this action may be attributed to the activated charcoal. Activated charcoal is known for high level oxidation potential which can destroy the cellular membranes of living organisms very rapidly by means of oxygen radicals, (TEM) and (SEM) Assessment. Under a defined electric field potentials microbe hardly withstand the intensity of radiant energy from the fields. Sale and Hamilton $(1961,1968)$

Another icon that enhances the EMF of destruction of microbes is the saline water. The saline water has a mixture of salt and water at a defined ratio $\mathrm{Na}^{+}$and $\mathrm{Cl}^{-}$radical. The sodium ion present in the medium brought about damaging of the microbes at the end due to partial electrolysis build up making the microbes to degenerate Vega-Mercado et al (1996). The intrusion of this liquid to the medium is made possible through the micro pores at the cellophane covering. However, the major area where the deaths of the microbes where experienced is at the central core of electromagnetic field which operates at a little temperature rise above the laboratory temperature.

The present study has reviewed the most current techniques of EMFs in antimicrobial studies and mechanisms of actions of these methods. The purpose of this review is to find out the most effective way of destroying microbes by the application of EMFs. In the findings carried out so far by researchers, it is found that pathogens are killed by subjecting to EMFs in ionic medium $\mathrm{pH}$. This is made more effective by manipulating the field to gain high field intensity with lesser time frame of action. This is achieved by novel inclusion of activated charcoal, glass beads and emulsified saline water. 


\section{0: $\quad$ CONCLUSION}

The EMFs techniques in appropriate parameters can be used for bacterial and microbial pathogens especially on surfaces suspected to be harboring these microbes. This is cogent considering the novel covid-19 pandemic. Also, for further establishment of new EMFs based techniques for antimicrobial and antibacterial purposes, it is further recommended that detailed experimental studies should be carried out using the designed experiments outlined above with robust funding from relevant agencies of government and the private sectors.

\section{0: REFERENCES}

Belis et al (2004) Effects of a static magnetic field on cell growth and gene expression in Eschericia coli. "mutation research/genetic toxicology and environmental mutagenesis 561(1-2) 53-62.

Bresser P. et al (2002). New strains of bacteria and exerbatious of COPD. N Engl S. med, vol 347, No 25- December19.

Bruhn et al (2016). Quantifying the relationship between Curvature and electric potential in lipid bilayers. J. phys.chem.B 2016, 120,21,4812-4817

Bush et al (2011). Methods for the differentiation of microorganisms. International journal of 2011 Elsevier.

Chang et al (2005). Genotoxicity evaluation of electromagnetic fields. European Journal of 2005- Journal of cancer prevention 14(2):175-9.

Costertonet al (1994). EMF exposure duration, genetic markers and bacterial depopulation.

Domingo E. Holland J. (1994). Mutation rates and rapid evolution of RNA viruses. Annual review in Microbiology, 1987-annual reviews. Org.

Dunlap, P. V. (2014). Biochemistry and genetics of bacteria bioluminescence. Bioluminescence fundamentals and applications in Biolotechnology - volume 1 Pp 37-64.

El-Sayed et al (2006) stimulation and control of E-coli by using an externally low frequency magnetic field. International Journal of Radiation Biology 87(12): 1155-61

Engelbrecht et al (1983). Bacterial bioluminescence; isolation and genetic analysis of functions. Cell, 1983 - Elsevier.

Fojt et al (2004). Comparison of the low frequency magnetic field effects on bacteria Escherichia coli, leclericiaadecarbhoxylata and staphylococousaereus. 2004- Elsevier science B.V. 
Falone et al (2007). Extremely low frequency magnetic field on Neuroblastoma cells. Journal of cellular Biochemistry 112(12): 3797-806.

Grassi et al (2001). Electromagnetic fields on voltage gates $\mathrm{Ca}_{2}+$ channels and their role in modulation and proliferation of death cell. 2004 April, 3594); 307-15.doi: 10.1016/j.ceca.2003.09.001.

Horiuchi et al (2001). Effects of a strong static magnetic fields on bacterium shewanellaoneidensis. Bioelectromagnetic/volume 28, issue 7.

Kohno et al (2000). Effects of low-density static magnetic fields on the growth and activities of wastewater bacteria. Pathophysiology 7(2):143-148.

Longton R.W. et al (1975). Isoelectric focusing of bacteria. Archives of oral biology, 1975Elsevier science B.V.

Lopocki et al (2005). Oxidative DNA damage in magnetic fields. Archive for pathology anatomy and physiology for clinical medicine. 446(6):634-9.

Mercado et al (1996). Inactivation of Escherichia coli by combining $\mathrm{pH}$ ionic strength and pulsed electric fields hurdles. Food Research international. Volume 29, issue 2, March 1996, page 117-121.

Novak et al (2005). Optical densities of S. cerevisiae. Bio electrochemistry, 200> - Elsevier science B.V.

Panagopoulus et al (2002). Mechanism for action of electromagnetic fields on cells. November 2002. Biochemical and Biophysical Research Communications. 298(1)95-102.

Piatti et al (2002). Antibacterial effect of a magnetic field on Serratia marcescens. July 2002. Comparative biochemistry and physiology part Biochemistry and molecular biology 13(2):359-65.

p. Free et al (2010). Classification of exposure to radio frequency. National Library of Medicine. Environ Int. 2010 Oct.

Philips J.L. et al (2009). Electromagnetic fields and DNA damage. Patholoplysiology 2009Elsevier Science B.V.

p. VZinin et al (2005). Mechanical resonances of bacterial cells. Phys Rev. E72, 6190(2005).

Sakakinar et al (1993). Impact of electromagnetism on organisms. Microbiological research Journal of membrane 2011-springer. 
Segatore et al (2012). Evaluations of the effects of extremely low-frequency electromagnetic fields on growth and antibiotic. International Journal of 2012.

Stansel et al (2001). Increased antibiotic resistance of E. coli exposed to static magnetic fields. Bioelectromagnetic 22(3);129-137.

Strasak et al (1998). The effect of low frequency electromagnetic fields on living organism. Saudi Journal of Biological sciences. Vol. 25 issue 1 Journal 2018 page 105.

Takehiko et al (2012). Scanning electron microscopy imaging of bacteria based on Nucleic Acids sequences. DIO:10.5772/36638, scanning electron microscopy March 2012.

Tsong (1991). Microbial inactivation by new technologies of food preservation. J Appl microbial. 2005;98(6):1387-99.

Vega-mercodo et al (1996). Inactivation of Escherichia coli by combining $\mathrm{pH}$ ionic strength and pulsed electric fields hurdles. Food res.Int.29,117-121.

Wenji et al (2009). Inhibited growth of E-coli by means of SMFs.

Weimin et al (2005). Effects of a strong static magnetic field on Bacterium ShewanellaOneidensis.Bioelectromagnetics 26(7)558-63.

XiaoxiaShjeng et al (2008). The influence of ionic strength, nutrients and $\mathrm{pH}$ on bacterial adhesion to materials. Journal of colloid and interface science 2008-elsevier Science B. $V$. 